\title{
El Pacto Internacional de Derechos Económicos, Sociales y Culturales: su aplicación efectiva respecto de la vivienda digna en la República Argentina The International Convention on Economic, Social and Cultural Rights: The Real and Effective Protection of Decent Housing in the Argentinean Republic
}

Sabrina Daniela Spaccarotella*

http://dx.doi.org/10.21503/lex.v15i19.1371

* Abogada UBA. Candidata a magíster en Derecho Procesal por la Universidad Nacional de Rosario. Docente de Derecho Constitucional Profundizado y Procesal Constitucional, Universidad de Buenos Aires. Docente de Contenidos de la Constitución Nacional y los Derechos Humanos, Universidad Nacional de Luján.

Correo de contacto: sabrinadspaccarotella@gmail.com

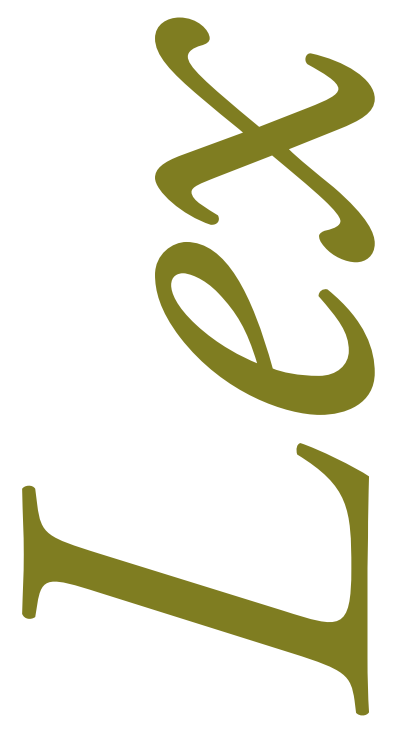

(c) (C) (C) Los autores. Artículo publicado por la Revista Lex de la Facultad de Derecho y Ciencias Políticas de la Universidad Alas Peruanas. Este es un artículo de acceso abierto, distribuido bajo los términos de la Licencia Creative Commons Atribución-No Comercial-Compartir Igual 4.0 Internacional.(http://creativecommons.org/licenses/by-nc-sa/4.0/), que permite el uso no comercial, distribución y reproducción en cualquier medio, siempre que la obra original sea debidamente citada. 


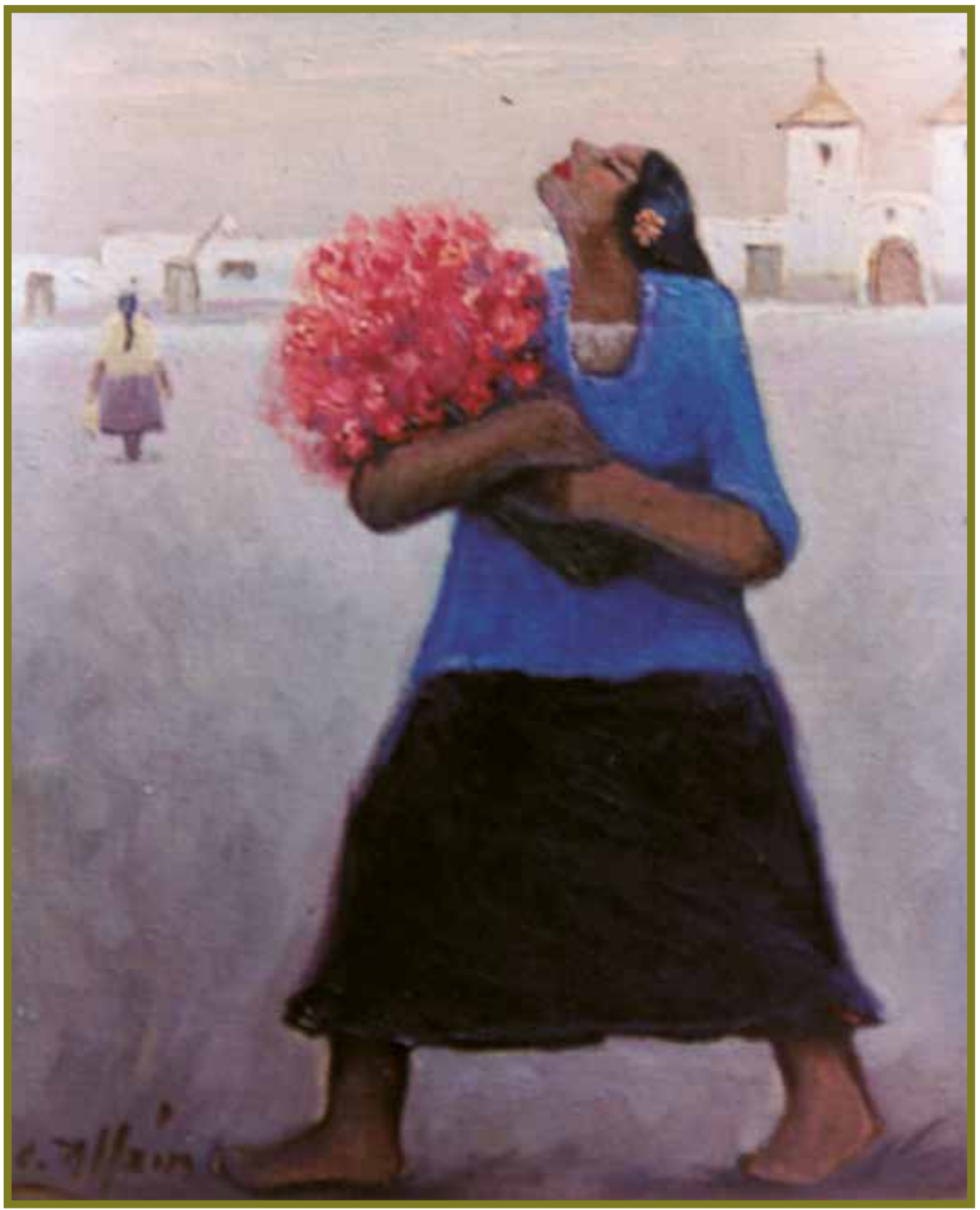

Florista. Óscar Allaín 


\section{RESUMEN}

Este artículo pretende hacer un pequeño análisis de la aplicación del Pacto Internacional de Derechos Económicos, Sociales y Culturales, específicamente en lo referido al acceso a una vivienda digna y adecuada en la República Argentina, y la respuesta que ha dado el Estado nacional a través de sus poderes (Poder Ejecutivo, Poder Legislativo, Poder Judicial) y los Estados provinciales mediante sus políticas y sentencias, a fin de alcanzar la concreción de este derecho reconocido internacionalmente en virtud del PIDESC e incorporado a la Constitución Nacional en su art. 75 inc. 22, otorgándole jerarquía superior a las leyes.

Palabras clave: vivienda digna, politica pública, derechos humanos.

\section{ABSTRACT}

This paper aims to briefly analyze the application of the International Convention on Economic, Social and Cultural Rights, specifically regarding the access to decent and adequate housing in Argentina and the response from the National Government through its powers (Executive, Legislative and Judiciary) and Provincial States through its policies and sentences, in order to achieve this right internationally recognized in the ICESCR (PIDESC in Spanish) and incorporated in the article 75.22 of the National Constitution, granting its superior hierarchy over regular laws.

Key words: decent housing; public policies; human rights. 


\section{INTRODUCCIÓN}

Hasta la adopción de la Carta de Naciones Unidas en 1945 y, más concretamente, la Declaración Universal de Derechos Humanos en 1948, no existen antecedentes de relevancia en los que se hayan consagrado derechos humanos con alcance universal. Debemos distinguir dos facetas del concepto de universalidad, puesto que este, como afirma Laporta, "como predicado de los derechos humanos hace usualmente referencia a los titulares de esos derechos y reviste una significación material o de contenido con respecto a ellos". En efecto, apunta a que los derechos son de todos los seres humanos (faz personal) y que deben ser respetados de manera uniforme (faz material) por todos los Estados de cualquier sistema político, de cualquier religión, y de cualquier tipo de costumbres sociales. No se concibe, hoy en día, la existencia de derechos humanos para algunos y no para otros, ni de derechos que sean distintos en una religión que en otra.

Ambos parámetros, a nuestro entender, integran el concepto de universalidad. ${ }^{1}$

Los derechos humanos en la actualidad no son pensados solo como un límite a la opresión y al autoritarismo estatal, sino también como un programa que puede guiar u orientar las políticas públicas y contribuir al fortalecimiento de los sistemas democráticos, en el marco de las diferencias culturales y de género. ${ }^{2}$

A diferencia de lo que aconteció en el siglo XIX y principios del XX, donde la centralidad del Estado estaba enfocada en la organización del poder, desde la mitad del siglo XX hasta la actualidad, el sistema de derechos configura el núcleo estructural de los Estados modernos. ${ }^{3}$

Pablo Luis Manili, "La difícil tarea de definir el concepto de derechos humanos", en Derechos humanos y control de convencionalidad, coordinado por Mario Midon (ConTexto, 2016), 13.

2 Luis E. Duacastella Arbizu y María Andrea Mercado, "La desprotección de la mujer en el programa de restauración del daño ambiental colectivo de la Cuenca Matanza - Riachuelo", Revista Institucional de la Defensa Pública de la Ciudad Autónoma de Buenos Aires, Año 4, N. ${ }^{\circ} 6$ (diciembre de 2014): 150.

3 Andrés Gil Domínguez. Derechos, racionalidad y última palabra, primera edición (Buenos Aires: Ediar, 2014), 29. 
Eduardo Jiménez entiende que los derechos humanos requieren su incorporación al ordenamiento jurídico positivo para realizarse o adquirir efectividad. Siendo, además, que es característica del derecho positivo, la derogabilidad de sus normas (a diferencia de los derechos naturales, imaginados por la filosofía), creemos que en un sistema jurídico moderno, con estructura estatal, los órganos de creación y aplicación del derecho actúan en el marco dispuesto por las normas fundamentales. ${ }^{4}$

\section{EL BLOQUE DE CONSTITUCIONALIDAD ${ }^{5}$ Y LA PROTECCIÓN DE LOS DERECHOS FUNDAMENTALES}

El Pacto Internacional de Derechos Económicos, Sociales y Culturales fue adoptado y abierto a la firma, ratificación y adhesión por la Asamblea General en su resolución 2200 A (XXI), del día 16 de diciembre de 1966. El mismo tuvo su entrada en vigor el 3 de enero de 1976, de conformidad con el artículo 27.

Argentina aprobó el Pacto por medio de la ley 23.313, sancionada el 17 de abril de 1986 y promulgada el 06 de mayo de 1986.

Este instrumento es uno de los tratados internacionales a los que el país está vinculado con la preeminencia que la Constitución Nacional les otorga conforme al art. 75, inc. 22, C.N. y con superioridad respecto de las normas internas.

En el fallo "Ekmekdjian c. Sofovich", ${ }^{6}$ y adelantándose a la reforma constitucional, ya la Corte Suprema de Justicia de la Nación Argentina afirmaba que los tratados aprobados por nuestro país son directamente operativos en el derecho interno e imperativos para los jueces si refieren a derechos humanos. Ingresan directa y automáticamente al derecho interno y deben interpretarse de buena fe. Entonces, el reconocimiento de los derechos económicos, sociales y culturales son indiscutiblemente obligatorios, tanto para los individuos como para el Estado.

El artículo 75 inciso 22 de la Constitución Nacional, además de establecer la jerarquía superior de los tratados frente a las leyes, tiene una excepción, ya que taxativamente enumera once tratados de derechos humanos, estableciendo que tienen jerarquía constitucional, es decir, que se encuentran en igual ubicación que la propia Ley Suprema. Además, el mismo artículo establece un mecanismo para la incorporación de otros instrumentos internacionales a esa misma jerarquía.

4 Eduardo Jimenes, “¿Qué son los derechos humanos?”, en Derechos humanos y control de convencionalidad, coordinado por Mario Midon (ConTexto, 2016), 21.

5 Ver Luis P. Manili, El bloque de constitucionalidad, la recepción del Derecho Internacional de los Derechos Humanos en el Derecho Constitucional Argentino (Bueno Aires: La Ley, 2003).

6 CSJN, Fallos 315: 1492, “Ekmekdjian, Miguel A. c. Sofovich Gerardo y otros”, sentencia 07.07.1992. 
Ese mecanismo ya se ha puesto en práctica al incorporar a esta categoría a la Convención Interamericana sobre la Desaparición Forzada de Personas, adoptada en la Asamblea General de la Organización de Estados Americanos (OEA), en Belem, Brasil, en 1994, y aprobada por nuestro país en 1995. Dado que esta norma fue aprobada por medio del mecanismo que prescribe la propia Constitución Nacional, se le otorga jerarquía constitucional a través de la Ley $\mathrm{N}^{\circ} 24.820$, también a la Convención sobre la Imprescriptibilidad de los Crímenes de Guerra y de los Crímenes de Lesa Humanidad, aprobada por la Ley N² 24.584 de 1995 y por la Ley $\mathrm{N}^{\circ} 25.778$ de 2003, y finalmente se incorpora la Convención sobre los Derechos de las Personas con Discapacidad, aprobada por la Ley No 27.044 el 19 de noviembre de 2014.

Es decir, existe pie de igualdad entre la Constitución Nacional y los instrumentos internacionales, formando lo que se conoce con el nombre de "bloque de constitucionalidad". Dentro de ese bloque se considera que ciertas normas que están por fuera de la Constitución comparten con esta su posición privilegiada dentro del ordenamiento jurídico.

Dentro de los once primeros tratados que fueron incorporados al bloque de constitucionalidad encontramos el Pacto Internacional de Derechos Económicos, Sociales y Culturales.

En atención a ello es que nuestro régimen interno debe estar en consonancia con lo que expresa el Pacto Internacional de Derechos Económicos, Sociales y Culturales y los demás instrumentos internacionales enunciados.

\section{CONTROL JUDICIAL DE CONVENCIONALIDAD}

En las últimas décadas, la incorporación del Estado Argentino - y, consecuentemente, de sus diferentes descentralizaciones federales, entre ellas, la Ciudad Autónoma de Buenos Aires - a los distintos sistemas internacionales de protección de los derechos humanos ha significado un verdadero giro copernicano en relación con las estrategias jurídicas que permiten asegurar la adecuada tutela de los derechos fundamentales, tanto en el ámbito interno como en el internacional. Ello es así por cuanto esta incorporación implica asumir el compromiso de respetar y hacer cumplir en ambos órdenes una extensa nómina de obligaciones vinculadas con los derechos que esos sistemas reconocen y protegen, y cuya eventual inobservancia tiene por efecto comprometer la responsabilidad internacional del Estado. De esta forma, la protección de los derechos humanos ha dejado de ser una tarea exclusiva de los tribunales locales, para transformarse en una incumbencia concurrente o compartida entre las jurisdicciones estatales e internacionales. ${ }^{7}$

Pablo C. Mantaras, "El control de convencionalidad en el ámbito del poder judicial de la ciudad autónoma de buenos aires. Perspectivas actuales y desafíos futuros", en Centro de Formación Judicial, 15 años del centro de formación judicial (Ciudad Autónoma de Buenos Aires: Jusbaires, 2014), 248. 
Fauda de Losada entiende que el control de convencionalidad, doctrina cuyo nacimiento se produce en el marco del derecho supraestatal, nos pone de frente a un verdadero cambio de época, cuyas consecuencias globalizantes no se alcanzan aún a vislumbrar. La importancia actual que han cobrado los derechos humanos está dada por su creciente fuerza jurídica, que se expresa no solo por su reconocimiento en numerosos tratados internacionales — generales, sectoriales, universales y regionales_ sino también por la creación de órganos jurisdiccionales o cuasijurisdiccionales para su defensa, promoción y garantía, cuyas decisiones producen un claro efecto expansivo sobre los ámbitos jurídicos internos.

Pero no solo la Corte Interamericana es responsable del control de convencionalidad, ya que este tribunal no ejerce una competencia exclusiva en la materia. Debemos recordar siempre que estamos en presencia de normas interconectadas, entre otras cosas, a una pluralidad de intérpretes. Los jueces nacionales son —en gran parte- los responsables de aplicar dicho control, pues el ingreso a la nombrada Corte está restringido por el carácter subsidiario de su intervención jurisdiccional. $\mathrm{Al}$ momento de interpretar la $\mathrm{CADH}$, los jueces nacionales deben seguir los estándares de protección elaborados por la Corte Interamericana, estando obligados a su aplicación en el caso concreto. Más aun, la Corte Interamericana entiende que el control de convencionalidad "es función y tarea de cualquier autoridad pública y no solo del Poder Judicial". ${ }^{8}$

La CIDH cumple un rol importantísimo en el esquema interamericano de protección de derechos humanos, porque cuenta con herramientas que se acomodan a la diversidad de situaciones de violación de derechos que se manifiestan en la región. La experiencia desde el inicio de las actividades de la CIDH ha permitido formular reformas importantes en la legislación interna de los Estados, modificando mecanismos procesales, incorporando garantías más idóneas, permitiendo la reapertura de procesos inconclusos y reforzando la exigencia de independencia de los órganos judiciales. ${ }^{9}$ Víctor Bazán ${ }^{10}$ entiende que vale tener presente que tanto en la etapa inicial de un proceso en el que se investigue la eventual violación de derechos humanos, cuando - en su caso- en la fase de ejecución de una sentencia de condena internacional de la Corte IDH,${ }^{11}$ la intervención de los órganos competentes nacionales

8 Calogero Pizzolo, "Las normas interconectadas. Entre la primera y la última palabra en derechos humanos", La Ley (08/07/2015):1. Cita online: AR/DOC/2156/2015.

9 Adelina Loianno, "Funcionamiento de los órganos de protección de los derechos humanos. Algunas cuestiones acerca de las condiciones de eficacia del SIDH", en Derechos humanos y control de convencionalidad, coordinado por Mario Midon (ConTexto, 2016), 29.

10 Víctor Bazán, "El control de la convencionalidad: incógnitas, desafíos y perspectivas", en Contextos, una publicación del Seminario de Derecho Público de la Defensoría del Pueblo de la Ciudad Autónoma de Buenos Aires, Nº 5 (abril de 2013): 9,10.

11 Corte IDH, Caso “Trabajadores cesados del Congreso (Aguado Alfaro y otros) vs. Perú”, sentencia de Excepciones Preliminares, Fondo, Reparaciones y Costas, 24 de noviembre de 2006, Serie C, No 158; voto razonado del Juez Sergio García Ramírez, párr. 11. 
resulta ineludible. Como es de sobra conocido, en principio, constituye recaudo esencial para franquear el acceso inicial al Sistema Interamericano el ya señalado agotamiento previo de los recursos internos, así como la existencia de una violación de derechos humanos que resulta no reparada integralmente en el espacio nacional. Análogamente, luego de un pronunciamiento de condena de un Estado por la Corte IDH que aquel no cumpla en tiempo y forma, sobrevendrá para la víctima, sus familiares o representantes legales la posibilidad de ejecutar ese decisorio ante los tribunales internos del demandado remisor.

\section{DOCTRINA DEL CONTROL DE CONVENCIONALIDAD}

La doctrina del control de convencionalidad tiene su nacimiento en el caso "Almonacid Arellano y otros vs. Chile" 12 del 26 de septiembre de 2006. La Corte en esa oportunidad expresó:

117. Esta Corte ha afirmado en varias oportunidades que en el derecho de gentes, una norma consuetudinaria prescribe que un Estado que ha celebrado un convenio internacional debe introducir en su derecho interno las modificaciones necesarias para asegurar la ejecución de las obligaciones asumidas. Esta norma aparece como válida universalmente y ha sido calificada por la jurisprudencia como un principio evidente (...). 124. (...) [C] uando un Estado ha ratificado un tratado internacional como la Convención Americana, sus jueces, como parte del aparato del Estado, también están sometidos a ella, lo que les obliga a velar porque los efectos de las disposiciones de la Convención no se vean mermadas por la aplicación de leyes contrarias a su objeto y fin, y que desde un inicio carecen de efectos jurídicos. En otras palabras, el Poder Judicial debe ejercer una especie de "control de convencionalidad" entre las normas jurídicas internas que aplican en los casos concretos y la Convención Americana sobre Derechos Humanos. En esta tarea, el Poder Judicial debe tener en cuenta no solamente el tratado, sino también la interpretación que del mismo ha hecho la Corte Interamericana, intérprete última de la Convención Americana.

En el caso "Trabajadores cesados del Congreso vs. Perú (Aguado Alfano y otros)", ${ }^{13}$ la Corte utilizó los argumentos del caso precedente "Almonacid Arellano y otros vs. Chile":

128. Cuando un Estado ha ratificado un tratado internacional como la Convención Americana, sus jueces también están sometidos a ella, lo que les obliga a velar porque el efecto útil de la Convención no se vea mermado o anulado por la aplicación de leyes contrarias a sus disposiciones, objeto y fin. En otras palabras, los órganos del Poder Judicial deben ejercer no solo un control de constitucionalidad, sino también "de convencionalidad" ex officio entre las normas internas y la Convención Americana, evidentemente en el marco de sus respectivas competencias y de las regulaciones procesales correspondientes. Esta función

12 Corte IDH, Caso "Almonacid Arellano y otros vs. Chile", sentencia 18.11.2010, párr. 117 y 124.

13 Corte IDH “Trabajadores cesados del Congreso vs. Perú (Aguado Alfano y otros)”, sentencia 24.112006, párr. 128. 
no debe quedar limitada exclusivamente por las manifestaciones o actos de los accionantes en cada caso concreto, aunque tampoco implica que ese control deba ejercerse siempre, sin considerar otros presupuestos formales y materiales de admisibilidad y procedencia de ese tipo de acciones.

La misma doctrina se reiteró de manera firme en el caso "La Cantuta vs. Perú" del 29 de noviembre de 2006, respecto del cual la Corte expresó:

173. Además, en cuanto a los alcances de la responsabilidad internacional del Estado al respecto, la Corte ha precisado recientemente que: [...] El cumplimiento por parte de agentes o funcionarios del Estado de una ley violatoria de la Convención produce responsabilidad internacional del Estado, y es un principio básico del derecho de la responsabilidad internacional del Estado, recogido en el Derecho Internacional de los Derechos Humanos, que todo Estado es internacionalmente responsable por actos u omisiones de cualesquiera de sus poderes u órganos en violación de los derechos internacionalmente consagrados, según el artículo 1.1 de la Convención Americana. [...] La Corte es consciente que los jueces y tribunales internos están sujetos al imperio de la ley y, por ello, están obligados a aplicar las disposiciones vigentes en el ordenamiento jurídico. Pero cuando un Estado ha ratificado un tratado internacional como la Convención Americana, sus jueces, como parte del aparato del Estado, también están sometidos a ella, lo que les obliga a velar porque los efectos de las disposiciones de la Convención no se vean mermadas por la aplicación de leyes contrarias a su objeto y fin, y que desde un inicio carecen de efectos jurídicos. En otras palabras, el Poder Judicial debe ejercer una especie de "control de convencionalidad" entre las normas jurídicas internas que aplican en los casos concretos y la Convención Americana sobre Derechos Humanos. En esta tarea, el Poder Judicial debe tener en cuenta no solamente el tratado, sino también la interpretación que del mismo ha hecho la Corte Interamericana, intérprete última de la Convención Americana. ${ }^{14}$

Luego se sucedieron las sentencias de "Boyce y otros vs. Barbados", ${ }^{15}$ "Heliodoro Portugal vs. Panamá", 16 "Rocendo Radilla Pacheco vs. México", 17 "Manuel Cepeda Vargas vs. Colombia", 18 "Comunidad indígena XakmokKasek vs. Paraguay", 19 "Fernández Ortega y otros vs. México", ${ }^{20}$ "Rosendo Cantú y otra vs. México", ${ }^{21}$ "Ibsen Cárdenas e Ibsen Peña vs. Bolivia", ${ }^{22}$ "Vélez Loor vs. Panamá", ${ }^{23}$ "Gómez Lund y otro (Guerrilha do Araguaia) vs.

14 Corte IDH, “La Cantuta vs. Perú”, sentencia 29.11.2006, párr. 173.

15 Del 20.11.007, reiterándose la doctrina en el párrafo 78.

16 Del 12.08.2008, reiterándose la doctrina en el párrafo 180.

17 Del 23.11.2009, reiterándose la doctrina en el párrafo 339.

18 Del 26.05.2010, reiterándose la doctrina en el párrafo 208.

19 Del 24.08.2010, reiterándose la doctrina en el párrafo 311.

20 Del 30.08.2010, reiterándose la doctrina en el párrafo 234.

21 Del 25.11.2010, reiterándose la doctrina en el párrafo 219.

22 Del 01.09.2010, reiterándose la doctrina en el párrafo 202.

23 Del 23.10.2010, reiterándose la doctrina en el párrafo 287. 
Brasil”, 24 "Cabrera García y Montiel Flores vs. México”, 25 "Gelman vs. Uruguay”26 y "López Mendoza vs. Venezuela". ${ }^{27}$

En el caso de la Argentina, la Corte Interamericana ha sentenciado en "Fontevecchia y D'amico vs. Argentina", ${ }^{28}$ con fecha 29 de noviembre de 2011, donde establece que

este Tribunal ha establecido en su jurisprudencia que es consciente que las autoridades internas están sujetas al imperio de la ley y, por ello, están obligadas a aplicar las disposiciones vigentes en el ordenamiento jurídico. Pero cuando un Estado es parte de un tratado internacional como la Convención Americana, dicho tratado obliga a todos sus órganos, incluidos sus jueces, quienes deben velar por que los efectos de las disposiciones de la Convención no se vean mermados por la aplicación de normas o interpretaciones contrarias a su objeto y fin. Los jueces y órganos vinculados a la administración de justicia en todos los niveles están en la obligación de ejercer ex officio un "control de convencionalidad" entre las normas internas y la Convención Americana, evidentemente en el marco de sus respectivas competencias y de las regulaciones procesales correspondientes. En esta tarea, los jueces y órganos vinculados a la administración de justicia deben tener en cuenta no solamente el tratado, sino también la interpretación que del mismo ha hecho la Corte Interamericana. (Párrafo 93.)

La sentencia mencionada ha sido receptada por nuestra Corte Suprema de Justicia de la Nación en el caso "Rodríguez Pereyra, Jorge Luis contra el Ejército Argentino", ${ }^{29}$ al señalar que

los órganos judiciales de los países que han ratificado la Convención Americana sobre Derechos Humanos están obligados a ejercer de oficio el control de convencionalidad, descalificando las normas internas que se opongan a dicho tratado. Resultaría, pues, un contrasentido aceptar que la Constitución Nacional que, por un lado, confiere rango constitucional a la mencionada Convención (art. 75, inc. 22), incorpora sus disposiciones al derecho interno y, por consiguiente, habilita la aplicación de la regla interpretativa — formulada por su intérprete auténtico, es decir, la Corte Interamericana de Derechos Humanos- que obliga a los tribunales nacionales a ejercer de oficio el control de convencionalidad, impida, por otro lado, que esos mismos tribunales ejerzan similar examen con el fin de salvaguardar su supremacía frente a normas locales de menor rango.(Considerando 12.)

24 Del 24.11.2010, reiterándose la doctrina en el párrafo 106.

25 Del 26.11.2010, reiterándose la doctrina en el párrafo 225.

26 Del 24.02.2011, reiterándose la doctrina en el párrafo 193.

27 Del 01.09.2011, reiterándose la doctrina en el párrafo 226.

28 Corte IDH, "Fontevecchia y D’amico vs. Argentina”, sentencia 29.11.2011, párr. 93.

29 CSJN, R.401. XLIII, "Rodríguez Pereyra, Jorge Luis contra el Ejército Argentino", sentencia 27.11.2012. 
Asimismo, en reiteradas oportunidades en los últimos años, nuestro Máximo Tribunal ha incorporado a sus sentencias el control de convencionalidad. Así podemos mencionar los casos de "García Méndez, Emilio", 30 "Emma Elidia Gualtieri Rugnone de Prieto y otros", ${ }^{31}$ "Mazzeo", "Videla, Jorge Rafael y Massera, Emilio Eduardo s/recurso de casación". ${ }^{33}$

Asimismo, podemos delimitar que el control de convencionalidad tiene ciertas características básicas: 1.- el Juez nacional es quien debe realizar el test de compatibilidad entre las leyes internas y los instrumentos internacionales, comportándose como magistrados interamericanos. 2.- todos los jueces nacionales deben ejercer este control. 3.- se debe realizar independientemente de que lo peticionen las partes en el proceso.

Luego, la Corte Interamericana podrá revisar en la instancia supranacional las actuaciones de los jueces nacionales — controlando, incluso, el correcto ejercicio del "control de convencionalidad" - cuando este análisis resulte significativo para determinar, en el marco de un caso llevado ante sus estrados, si el Estado (del cual el juez nacional es un órgano) ha cumplido fielmente con las obligaciones asumidas en la Convención Americana de acuerdo con lo establecido por la jurisprudencia convencional. ${ }^{34}$

Conforme se viene analizando, el control de convencionalidad está ligado a las obligaciones que los Estados asumen al firmar y ratificar tratados de derechos humanos; en este punto, le corresponde al Poder Judicial aplicar los mismos "en las condiciones de su vigencia". En tal sentido, especial relevancia reviste la temática de los derechos económicos, sociales y culturales, que por su naturaleza progresiva imponen a los Estados el deber de diseñar, planificar, y controlar programas necesarios para garantizar su goce, siendo una legislación que los proclame insuficiente, si la conducta de los tres poderes no se orienta a permitir el desarrollo integral de la persona. ${ }^{35}$

Los Estados parte se comprometen a adoptar todas las medidas legislativas necesarias para el pleno ejercicio de los derechos reconocidos en la Convención, además de abordar las relaciones internacionales de manera que paulatinamente los ciudadanos gocen de los derechos reconocidos (art. $2^{\circ}$ y 26 Convención Americana de Derechos Humanos). ${ }^{36}$

30 CSJN, G.147. XLIV, “García Méndez, Emilio y Musa, Laura Cristina s/ causa N 7537”, sentencia 02.12.2008.

31 CSJN, G. 291. XLIII, "Gualtieri Rugnone de Prieto, Emma Elidia y otros s/ sustracción de menores de 10 años”, sentencia 11.08.2009.

32 CSJN, Fallos 330:3248, sentencia 13.07.2007.

33 CSJN, Fallos 330:3248, sentencia 31.08.2010.

34 CSJN, Fallos 330:3248, sentencia 31.08.2010.

35 CSJN, Fallos 330:3248, sentencia 31.08.2010.

36 Artículo 2. Deber de adoptar disposiciones de derecho interno. Si el ejercicio de los derechos y libertades mencionados en el artículo 1 no estuviere ya garantizado por disposiciones legislativas o de otro carácter, los Estados Parte se comprometen a adoptar, con arreglo a sus procedimientos constitucionales y a las disposiciones de esta Convención, las medidas legislativas o de otro carácter que fueren necesarias para hacer efectivos tales derechos y libertades. Derechos económicos, sociales y culturales. 


\section{LOS DERECHOS ECONÓMICOS, SOCIALES Y CULTURALES Y EL ACCESO A LA VIVIENDA DIGNA}

En el Pacto Internacional de Derechos Económicos, Sociales y Culturales se establece que los Estados deben "adoptar medidas" hasta el máximo de los recursos de que dispongan para lograr progresivamente la plena efectividad de los derechos económicos, sociales y culturales.

El concepto de "realización progresiva" describe un aspecto esencial de las obligaciones de los Estados en relación con los derechos económicos, sociales y culturales en el marco de los tratados internacionales de derechos humanos. La referencia a la "disponibilidad de los recursos" es una forma de reconocer que la efectividad de tales derechos puede verse obstaculizada por la falta de recursos y que puede lograrse únicamente a lo largo de cierto período de tiempo. Paralelamente, significa que el cumplimiento por un Estado de sus obligaciones de adoptar medidas apropiadas se evalúa teniendo en cuenta los recursos —económicos y de otra índole- de que dispone.

Además, muchas constituciones nacionales prevén el logro progresivo de la efectividad de algunos derechos económicos, sociales y culturales. ${ }^{37}$

Bazán entiende que es también imprescindible tener en cuenta que la canalización jurisdiccional de los derechos económicos, sociales y culturales es la consecuencia de que existan derechos genuinos y no meras expectativas, esperanzas o promesas desprovistas de anclaje real. Como hipótesis de mínima, debe admitirse que los derechos sociales presentan alguna veta de justiciabilidad que debe ser resguardada para evitar que se diluya el núcleo esencial del derecho en cuestión, punto este que se perfila como un peculiar desafío para el Estado Constitucional y Convencional y para un bien entendido activismo judicial. En línea, se ubica la Observación General (O. G.) No 9 del Comité de Derechos Económicos, Sociales y Culturales de la Organización de Naciones Unidas, referida a "La aplicación interna del Pacto Internacional de Derechos Económicos, Sociales y Culturales”, del 3 de diciembre de 1998. En ella se ha subrayado que la adopción de una clasificación rígida de los DESC que los sitúe, por definición, fuera del ámbito de los tribunales sería arbitraria e incompatible con el principio de que los dos "grupos" de derechos [refiriéndose a los DESC y a los civiles y políticos] son indivisibles e interdependientes, al tiempo que "reduciría drásticamente la capacidad de

\footnotetext{
Artículo 26. Desarrollo progresivo. Los Estados parte se comprometen a adoptar providencias, tanto a nivel interno como mediante la cooperación internacional, especialmente económica y técnica, para lograr progresivamente la plena efectividad de los derechos que se derivan de las normas económicas, sociales y sobre educación, ciencia y cultura, contenidas en la Carta de la Organización de los Estados Americanos, reformada por el Protocolo de Buenos Aires, en la medida de los recursos disponibles, por vía legislativa u otros medios apropiados.
}

37 Idem. 
los tribunales para proteger los derechos de los grupos más vulnerables y desfavorecidos de la sociedad". ${ }^{38}$

Con el objeto de asegurar el cumplimiento del Pacto, el mismo establece que los Estados parte deberán presentar informes en los que se establezcan las medidas adoptadas para el cumplimiento del mismo. ${ }^{39}$

En lo relativo a la vivienda digna, el instrumento prevé en su artículo 11 punto $1,{ }^{40}$ que los Estados reconocen el derecho que posee todo ser humano a una vivienda adecuada. La Observación General No 4 ("El derecho a una vivienda adecuada, párrafo 1 del artículo 11 del Pacto") establece qué debemos comprender cuando hablamos de "vivienda adecuada", interpretando que el derecho a la vivienda ${ }^{41}$ no puede ser entendido en forma restringida sino en un sentido absolutamente amplio que incluye el derecho de vivir en seguridad, paz y dignidad. Además, esa vivienda a la que se refiere debe tener la característica de ser adecuada, es decir, que la misma cuente con lo necesario para el desarrollo, esparcimiento, seguridad e higiene, disponibilidad de servicios, gastos soportables, seguridad jurídica de la tenencia, y debe encontrarse en un lugar que permita el acceso a un empleo, atención sanitaria, escuelas, servicios sociales, de quien viva en ella. Además, resulta indispensable que el acceso a esa vi-

38 Víctor Bazán, "Hacia la justiciabilidad directa de los derechos económicos, sociales y culturales en el sistema interamericano", La Ley (11/02/2015): 1

39 Pacto Internacional de Derechos Económicos, Sociales y Culturales. Parte IV. Artículo 16: 1. Los Estados Parte en el presente Pacto se comprometen a presentar, en conformidad con esta parte del Pacto, informes sobre las medidas que hayan adoptado, y los progresos realizados, con el fin de asegurar el respeto a los derechos reconocidos en el mismo. 2. a) Todos los informes serán presentados al Secretario General de las Naciones Unidas, quien transmitirá copias al Consejo Económico y Social para que las examine conforme a lo dispuesto en el presente Pacto; b) El Secretario General de las Naciones Unidas transmitirá también a los organismos especializados copias de los informes, o de las partes pertinentes de estos, enviados por los Estados parte en el presente Pacto que además sean miembros de estos organismos especializados, en la medida en que tales informes o partes de ellos tengan relación con materias que sean de la competencia de dichos organismos conforme a sus instrumentos constitutivos.

40 Artículo 11 punto 1. Los Estados parte en el presente Pacto reconocen el derecho de toda persona a un nivel de vida adecuado para sí y su familia, incluso alimentación, vestido y vivienda adecuados, y a una mejora continua de las condiciones de existencia. Los Estados parte tomarán medidas apropiadas para asegurar la efectividad de este derecho, reconociendo a este efecto la importancia esencial de la cooperación internacional fundada en el libre consentimiento.

41 En opinión del Comité, el derecho a la vivienda no se debe interpretar en un sentido estricto o restrictivo que lo equipare, por ejemplo, con el cobijo que resulta del mero hecho de tener un tejado por encima de la cabeza o lo considere exclusivamente como una comodidad. Debe considerarse más bien como el derecho a vivir en seguridad, paz y dignidad en alguna parte. Y así debe ser por lo menos por dos razones. En primer lugar, el derecho a la vivienda está vinculado por entero a otros derechos humanos y a los principios fundamentales que sirven de premisas al Pacto. Así pues, "la dignidad inherente a la persona humana", de la que se dice que se derivan los derechos del Pacto, exige que el término "vivienda" se interprete en un sentido que tenga en cuenta otras diversas consideraciones, y principalmente que el derecho a la vivienda se debe garantizar a todos, sean cuales fueren sus ingresos o su acceso a recursos económicos. En segundo lugar, la referencia que figura en el párrafo 1 del artículo 11 no se debe entender en sentido de vivienda a secas, sino de vivienda adecuada. Como han reconocido la Comisión de Asentamientos Humanos y la Estrategia Mundial de Vivienda hasta el Año 2000 en su párrafo 5, "el concepto de 'vivienda adecuada'... significa disponer de un lugar donde poderse aislar si se desea, espacio adecuado, seguridad adecuada, iluminación y ventilación adecuadas, una infraestructura básica adecuada y una situación adecuada en relación con el trabajo y los servicios básicos, todo ello a un costo razonable”. 
vienda adecuada esté al alcance de quienes se encuentren en situación de vulnerabilidad social y de quienes por sus características particulares se encuentren excluidos, como los ancianos, los niños, los discapacitados, quienes padecen enfermedades terminales, quienes viven con problemas médicos crónicos. ${ }^{42}$

42 Así pues, el concepto de adecuación es particularmente significativo en relación con el derecho a la vivienda, puesto que sirve para subrayar una serie de factores que hay que tener en cuenta al determinar si determinadas formas de vivienda se puede considerar que constituyen una "vivienda adecuada" a los efectos del Pacto. Aun cuando la adecuación viene determinada en parte por factores sociales, económicos, culturales, climatológicos, ecológicos y de otra índole, el Comité considera que, aun así, es posible identificar algunos aspectos de ese derecho que deben ser tenidos en cuenta a estos efectos en cualquier contexto determinado. Entre esos aspectos figuran los siguientes: a) Seguridad jurídica de la tenencia. La tenencia adopta una variedad de formas, como el alquiler (público y privado), la vivienda en cooperativa, el arriendo, la ocupación por el propietario, la vivienda de emergencia y los asentamientos informales, incluida la ocupación de tierra o propiedad. Sea cual fuere el tipo de tenencia, todas las personas deben gozar de cierto grado de seguridad de tenencia que les garantice una protección legal contra el desahucio, el hostigamiento u otras amenazas. Por consiguiente, los Estados parte deben adoptar inmediatamente medidas destinadas a conferir seguridad legal de tenencia a las personas y los hogares que en la actualidad carezcan de esa protección consultando verdaderamente a las personas y grupos afectados. b) Disponibilidad de servicios, materiales, facilidades e infraestructura. Una vivienda adecuada debe contener ciertos servicios indispensables para la salud, la seguridad, la comodidad y la nutrición. Todos los beneficiarios del derecho a una vivienda adecuada deberían tener acceso permanente a recursos naturales y comunes, a agua potable, a energía para la cocina, la calefacción y el alumbrado, a instalaciones sanitarias y de aseo, de almacenamiento de alimentos, de eliminación de desechos, de drenaje y a servicios de emergencia. c) Gastos soportables. Los gastos personales o del hogar que entraña la vivienda deberían ser de un nivel que no impidiera ni comprometiera el logro y la satisfacción de otras necesidades básicas. Los Estados parte deberían adoptar medidas para garantizar que el porcentaje de los gastos de vivienda sean, en general, conmensurados con los niveles de ingreso. Los Estados parte deberían crear subsidios de vivienda para los que no pueden costearse una vivienda, así como formas y niveles de financiación que correspondan adecuadamente a las necesidades de vivienda. De conformidad con el principio de la posibilidad de costear la vivienda, se debería proteger por medios adecuados a los inquilinos contra niveles o aumentos desproporcionados de los alquileres. En las sociedades en que los materiales naturales constituyen las principales fuentes de material de construcción de vivienda, los Estados parte deberían adoptar medidas para garantizar la disponibilidad de esos materiales. d) Habitabilidad. Una vivienda adecuada debe ser habitable, en sentido de poder ofrecer espacio adecuado a sus ocupantes y de protegerlos del frío, la humedad, el calor, la lluvia, el viento u otras amenazas para la salud, de riesgos estructurales y de vectores de enfermedad. Debe garantizar también la seguridad física de los ocupantes. El Comité exhorta a los Estados parte a que apliquen ampliamente los Principios de Higiene de la Vivienda[v] preparados por la OMS, que consideran la vivienda como el factor ambiental que con más frecuencia está relacionado con las condiciones que favorecen las enfermedades en los análisis epidemiológicos; dicho de otro modo, que una vivienda y unas condiciones de vida inadecuadas y deficientes se asocian invariablemente a tasas de mortalidad y morbilidad más elevadas. e) Asequibilidad. La vivienda adecuada debe ser asequible a los que tengan derecho. Debe concederse a los grupos en situación de desventaja un acceso pleno y sostenible a los recursos adecuados para conseguir una vivienda. Debería garantizarse cierto grado de consideración prioritaria en la esfera de la vivienda a los grupos desfavorecidos como las personas de edad, los niños, los incapacitados físicos, los enfermos terminales, los individuos VIH positivos, las personas con problemas médicos persistentes, los enfermos mentales, las víctimas de desastres naturales, las personas que viven en zonas en que suelen producirse desastres, y otros grupos de personas. Tanto las disposiciones como la política en materia de vivienda deben tener plenamente en cuenta las necesidades especiales de esos grupos. En muchos Estados parte, el mayor acceso a la tierra por sectores desprovistos de tierra o empobrecidos de la sociedad debería ser el centro del objetivo de la política. Los Estados deben asumir obligaciones apreciables destinadas a apoyar el derecho de todos a un lugar seguro para vivir en paz y dignidad, incluido el acceso a la tierra como derecho. f) Lugar. La vivienda adecuada debe encontrarse en un lugar que permita el acceso a las opciones de empleo, los servicios de atención de la salud, centros de atención para niños, escuelas y otros servicios sociales. Esto es particularmente cierto en ciudades grandes y zonas rurales donde los costos temporales y financieros para llegar a los lugares de trabajo y volver de ellos puede imponer exigencias excesivas en los presupuestos de las familias pobres. De manera semejante, la vivienda no debe construirse en lugares contaminados ni en la proximidad inmediata de fuentes de contaminación que amenazan el derecho a la salud de los habitantes. g) Adecuación cultural. La manera en que se construye la vivienda, los materiales 


\section{LA PROTECCIÓN DE LA VIVIENDA EN LA CONSTITUCIÓN NACIONAL Y CONSTITUCIONES PROVINCIALES}

Los derechos económicos, sociales y culturales son los derechos que procuran dar respuesta a las necesidades derivadas de una existencia digna y de relación con el prójimo. Constituyendo una constelación compleja y heterogénea, cuyo reconocimiento es fruto de la modificación del paradigma liberal — dominante en el primer constitucionalismo— según el cual las necesidades derivadas de la subsistencia y la vida de relación debían ser ajenas a la preocupación pública, quedando a merced del mercado o la beneficencia. El nuevo paradigma asumió la preocupación por estos temas de otra perspectiva: a) formuló una ponderación situada y no meramente teórica del ser humano, incorporando su dimensión familiar y social; b) consideró que el acceso al trabajo y las condiciones en las que este se desarrollaba no debían ser indiferentes a la preocupación publica, no solo por estar comprometida la supervivencia sino por involucrar a la dignidad humana; y c) estimó que las contingencias negativas o inevitables de la vida, tales como la enfermedad, la discapacidad o la vejez no podían convertir a un sector de la población en ciudadanos de segunda categoría; d) ponderó que el hombre no solo debe ser considerado como Homo sapiens y como Homo faber sino también como Homo ludens, integrando las necesidades (luego derechos) vinculadas con el esparcimiento, el goce del medio ambiente, etcétera. ${ }^{43}$

Tanto la Ley Suprema de la Nación, ${ }^{44}$ como las Constituciones provinciales han incorporado en su mayoría la protección de la vivienda.

Nuestra Constitución Nacional en su art. 14 bis, consagra "la protección integral de la familia; la defensa del bien de familia; la compensación económica familiar y el acceso a una vivienda digna". Asimismo, ha incluido dentro de los once primeros instrumentos internacionales con jerarquía constitucional al Pacto Internacional de Derechos Económicos, Sociales y Culturales (art. 75 inc. 22).

Mientras que la Constitución de la Ciudad Autónoma de Buenos Aires, ${ }^{45}$ en el Preámbulo sienta sus bases en los derechos humanos entre otros, y además en su artículo 10 adecua su organización interna en consonancia con la Constitución Nacional y los instrumentos internacionales. Asimismo, en su art. 20 establece que "se garantiza el derecho a la salud integral

de construcción utilizados y las políticas en que se apoyan deben permitir adecuadamente la expresión de la identidad cultural y la diversidad de la vivienda. Las actividades vinculadas al desarrollo o la modernización en la esfera de la vivienda deben velar por que no se sacrifiquen las dimensiones culturales de la vivienda y por que se aseguren, entre otros, los servicios tecnológicos modernos.

43 Horacio Rosatti, Tratado de derecho constitucional, tomo I, primera edición (Santa Fe: Rubinzal Culzoni, 2010), 123 y 124.

44 Sancionada por el Congreso General Constituyente el 1 de mayo de 1853, reformada y concordada por la Convención Nacional ad hoc el 25 de septiembre de 1860 y con las reformas de las convenciones de 1866, 1898, 1957 y 1994.

45 Dada en la sala de sesiones de la Convención Constituyente de la ciudad de buenos aires, el primero del mes de octubre del año mil novecientos noventa y seis. 
que está directamente vinculada con la satisfacción de necesidades de alimentación, vivienda, trabajo, educación, vestido, cultura y ambiente", reconoce específicamente el derecho a una vivienda digna y adecuada, en esos términos en su art. 31 estableciendo que

la Ciudad reconoce el derecho a una vivienda digna y a un hábitat adecuado. Para ello: Resuelve progresivamente el déficit habitacional, de infraestructura y servicios, dando prioridad a las personas de los sectores de pobreza crítica y con necesidades especiales de escasos recursos. Auspicia la incorporación de los inmuebles ociosos, promueve los planes autogestionados, la integración urbanística y social de los pobladores marginados, la recuperación de las viviendas precarias y la regularización dominial y catastral, con criterios de radicación definitiva.

En consonancia con los estándares internacionales en el art. 38 indica que

la Ciudad incorpora la perspectiva de género en el diseño y ejecución de sus políticas públicas y elabora participativamente un plan de igualdad entre varones y mujeres. Estimula la modificación de los patrones socioculturales estereotipados con el objeto de eliminar prácticas basadas en el prejuicio de superioridad de cualquiera de los géneros; promueve que las responsabilidades familiares sean compartidas; fomenta la plena integración de las mujeres a la actividad productiva, las acciones positivas que garanticen la paridad en relación con el trabajo remunerado, la eliminación de la segregación y de toda forma de discriminación por estado civil o maternidad; facilita a las mujeres único sostén de hogar, el acceso a la vivienda, al empleo, al crédito y a los sistemas de cobertura social; desarrolla políticas respecto de las niñas y adolescentes embarazadas, las ampara y garantiza su permanencia en el sistema educativo; provee a la prevención de violencia física, psicológica y sexual contra las mujeres y brinda servicios especializados de atención; ampara a las víctimas de la explotación sexual y brinda servicios de atención; promueve la participación de las organizaciones no gubernamentales dedicadas a las temáticas de las mujeres en el diseño de las políticas públicas. Regula los establecimientos que brindan alojamiento temporario, cuidando excluir los que encubran locaciones.

Además de promover para los jóvenes el acceso una vivienda, ${ }^{46}$ también tiene en cuenta a los excombatientes de la guerra del Atlántico Sur residentes en la Ciudad. ${ }^{47}$

46 Juventud. Artículo 40.- La Ciudad garantiza a la juventud la igualdad real de oportunidades y el goce de sus derechos a través de acciones positivas que faciliten su integral inserción política y social y aseguren, mediante procedimientos directos y eficaces, su participación en las decisiones que afecten al conjunto social o a su sector. Promueve su acceso al empleo, vivienda, créditos y sistema de cobertura social. Crea en el ámbito del Poder Ejecutivo y en las comunas, áreas de gestión de políticas juveniles y asegura la integración de los jóvenes. Promueve la creación y facilita el funcionamiento del Consejo de la Juventud, de carácter consultivo, honorario, plural e independiente de los poderes públicos.

47 Vigesimoprimera:

Los excombatientes de la guerra del Atlántico Sur residentes en la ciudad y que carezcan de suficiente cobertura social tendrán preferencia en los servicios o programas de salud, vivienda, trabajo, educación, capacitación profesional y en el empleo público. 
Asimismo, la provincia de Buenos Aires, ${ }^{48}$ en su Constitución, art. 11, establece: "Los habitantes de la Provincia son iguales ante la ley, y gozan de los derechos y garantías que establece la Constitución Nacional, los que emanan en su consecuencia a través de los tratados celebrados por la Nación y los que se expresan en esta Constitución (...)”. La provincia de Corrientes ${ }^{49}$ en su Constitución establece en el art. 39 que

la familia es el núcleo primario y fundamental de la sociedad y goza de las condiciones económicas, culturales y sociales que propendan a su desarrollo y protección integral. El Estado Provincial debe establecer políticas que faciliten su constitución y fortalecimiento, incluyendo el derecho al acceso y la preservación de la vivienda familiar única como institución social. Debe promover la asistencia familiar en lo que respecta a la vivienda, el empleo, el crédito y la cobertura social.

En la provincia de Santa $\mathrm{Fe}^{50}$ se establece en su Constitución que "el Estado crea las condiciones necesarias para procurar a sus habitantes un nivel de vida que asegure su bienestar y el de sus familias, especialmente por la alimentación, el vestido, la vivienda, los cuidados médicos y los servicios sociales necesarios" (...) (art. 21). Y en su art. 27 establece que "la Provincia estimula y protege el ahorro popular en todas sus formas y lo orienta hacia la propiedad de la vivienda urbana y del predio para el trabajo rural e inversiones en actividades productivas dentro del territorio de la Provincia”. En la Constitución de la provincia del Chaco ${ }^{51}$ se establece dentro de los derechos de los que gozan los trabajadores el de proporcionarle una vivienda higiénica y decorosa. ${ }^{52}$ En lo que respecta al núcleo familiar la Carta Magna local dispone en su art. 35 que "el Estado protege integralmente a la familia y le asegura las condiciones necesarias para su constitución regular, su unidad, su afianzamiento, el acceso a la vivienda digna y al bien de familia". Además, se otorga la posibilidad de créditos para la obtención de una vivienda tal como establece el art. 42 inc. $4,{ }^{53}$ y el art. 59 en relación a los impuestos dice que “(...) Las leyes de carácter tributario propenderán a la eliminación o

48 En la Sala de la Honorable Convención Constituyente, en la ciudad de La Plata, a los trece días del mes de septiembre de 1994.

49 Dada en la Sala de Sesiones de la Honorable Convención Constituyente de la Provincia de Corrientes, a los ocho días del mes de junio del año dos mil siete.

50 Dada en la sala de sesiones de la Honorable Convención de Santa Fe, a los catorce días del mes de abril del año mil novecientos sesenta y dos.

51 Dada en la sala de sesiones de la Cámara de Diputados, recinto de la Convención Constituyente, a los veintisiete días del mes de octubre del año mil novecientos noventa y cuatro.

52 Derechos del trabajador. Artículo 29. Todo trabajador goza de los siguientes derechos: (...) 6) A la seguridad en el trabajo, en forma de que su salud y moral estén debidamente preservadas. Los trabajos nocturnos, los peligrosos y los insalubres deberán ser convenientemente regulados y controlados. Normas especiales tutelarán el trabajo de las mujeres y de los menores. A los trabajadores rurales deberá proporcionarse vivienda higiénica y decorosa y controlarse su abastecimiento (...).

53 Artículo 42. El régimen de división o adjudicación de la tierra pública será establecido por ley, con sujeción a planes de colonización, con fines de fomento, desarrollo y producción que prevean: (...) 4) La seguridad del crédito oficial con destino a la vivienda y a la producción, el asesoramiento y la asistencia técnica. (...). 
reducción de los impuestos que recaigan sobre los artículos y servicios de primera necesidad, sobre los ingresos de los sectores de menores recursos de la población y sobre la vivienda familiar. (...)".

La provincia de Neuquén ${ }^{54}$ establece en su Constitución dentro de los derechos de los trabajadores, en el art. 38, que se garantizan "condiciones de trabajo que aseguren la salud, el bienestar, la vivienda, la educación y la asistencia médica y farmacéutica" ${ }^{55}$ En lo que respecta a perspectiva de género e igualdad de oportunidades, el art 45 establece que se facilitará "a las mujeres único sostén de familia el derecho a la vivienda, al empleo, al crédito y a los sistemas de cobertura social". Asimismo, el art. 48 promueve a los jóvenes "su acceso al empleo, vivienda, crédito y sistema de cobertura social".

En la Constitución de Tierra del Fuego, Antártida e Islas del Atlántico Sur ${ }^{56}$ se establece en su art. 23 que "todo habitante tiene derecho a acceder a una vivienda digna que satisfaga sus necesidades mínimas y de su núcleo familiar. A este fin, el Estado Provincial procurará el acceso a la propiedad de la tierra y dictará leyes especiales que implementarán los planes de vivienda”. Asimismo, el art. 28 dice que

la familia es el núcleo fundamental de la sociedad y debe gozar de condiciones sociales, económicas y culturales que propendan a su afianzamiento y desarrollo integral. El Estado Provincial la protege y le facilita su constitución y fines. El cuidado y la educación de los hijos es un derecho y una obligación de los padres. El Estado Provincial asegura su cumplimiento. Se reconoce el derecho a proteger una vivienda como bien de familia. Se dictará una ley preventiva de la violencia en la familia.

En la Constitución de la provincia de Santa Cruz, ${ }^{57}$ su artículo 55 expresa que la provincia establecerá un régimen de seguridad social que contribuirá a la construcción de viviendas higiénicas. ${ }^{58}$

54 Dada en la sala de sesiones de la Convención Constituyente de la provincia del Neuquén, a los diecisiete días de febrero de dos mil seis.

55 Derechos de los trabajadores. Art. 38. La Provincia, mediante la sanción de leyes especiales, asegurará a todo trabajador en forma permanente y definitiva lo siguiente: (...) Condiciones de trabajo que aseguren la salud, el bienestar, la vivienda, la educación y la asistencia médica y farmacéutica (...).

56 Dada en la Sala de Sesiones de la Convención Constituyente de la provincia de Tierra del Fuego, Antártida e Islas del Atlántico Sur, a los diecisiete (17) días del mes de mayo de 1991.

57 Dada en sala de sesiones de la Honorable Convención Constituyente, a los veintisiete días del mes de noviembre del año mil novecientos noventa y ocho, en la ciudad de Río Gallegos, capital de la provincia de Santa Cruz.

58 Artículo 55. La Provincia establecerá un régimen de seguridad social que comprenda a toda la población durante el transcurso de la vida humana, contemplando las consecuencias económicas y sociales de la desocupación, nacimiento, maternidad, enfermedad, desamparo, invalidez y muerte; fomentará las instituciones de solidaridad social, los establecimientos de ahorro y fomentará y contribuirá a la construcción de viviendas higiénicas. 
VII. ANÁLISIS JURISPRUDENCIAL RESPECTO DE LA APLICACIÓN DEL PIDESC: A) CIUDAD AUTÓNOMA DE BUENOS AIRES, B) BUENOS AIRES, C) CORRIENTES, D) SANTA FE, E) CHACO, F) NEUQUÉN, G) TIERRA DEL FUEGO E ISLAS DEL ATLÁNTICO SUR, H) SANTA CRUZ

\section{A. Ciudad Autónoma de Buenos Aires}

En la Ciudad Autónoma de Buenos Aires, en el caso "GCBA s/ queja por recurso de inconstitucionalidad denegado en: K.M.P c/ GCBA y otros s/ amparo (art. 14 CCABA)",59 el Tribunal Superior de Justicia condena al Gobierno de la Ciudad que presente al juez de grado una propuesta para hacer frente a la obligación de brindar a la parte actora un alojamiento que reúna las condiciones adecuadas, teniendo en cuenta las circunstancias probadas en la causa ya que el actor relató que tenía 49 años de edad, sin familiares, que padecía HIV y que se encontraba desempleado. Revocando la sentencia de Cámara que ordenó al GCBA que

...cubra [al accionante] la necesidad mínima de vivienda (...) por medio del subsidio que venía otorgando hasta ahora u otro medio razonable que disponga que no sea parador ni hogar, adecuado a la situación particular del actor y en el monto necesario para satisfacer la necesidad habitacional mínima existente, debiendo realizar una primera evaluación socioambiental dentro del mes de quedar firme la sentencia y, en lo sucesivo, en forma trimestral.

Para así decidir, los jueces de la Sala II consideraron que según los artículos 31 y 17 de la Constitución de la Ciudad y el PIDESC, el Estado tiene la obligación de avanzar tras el objetivo de la plena efectividad del derecho a la vivienda, que debe ser adecuada, con criterio de progresividad.

Los casos "GCBA s/ queja por recurso de inconstitucionalidad denegado en: Duhalde, Alejandra Viviana c/ GCBA y otros s/ amparo (art. 14 CCABA)", 60 "GCBA s/ queja por recurso de inconstitucionalidad denegado en: Sarubbi, Rosa Haydee y otros c/ GCBA y otros s/ amparo (art. 14 CCABA)", ${ }^{1}$ "GCBA s/ queja por recurso de inconstitucionalidad denegado en: R.Z.B. c/ GCBA s/ amparo (art. 14 CCABA)"62 y "Veiga Da Costa, Rocío c/ GCBA

59 TSJ, "GCBA s/ queja por recurso de inconstitucionalidad denegado en: K.M.P c/ GCBA y otros s/ amparo (art. 14 CCABA)”, Expte. 9205/12, sentencia 21.03.2014.

60 TSJ "GCBA s/ queja por recurso de inconstitucionalidad denegado en: Duhalde, Alejandra Viviana c/ GCBA y otros s/ amparo (art. 14 CCABA)", Expte. No 10954/14, sentencia 04.02.15.

61 TSJ, "GCBA s/ queja por recurso de inconstitucionalidad denegado en: Sarubbi, Rosa Haydee y otros c/ GCBA y otros s/ amparo (art. 14 CCABA)”, Expte. No 10695/14, sentencia, 17.12.14.

62 TSJ, "GCBA s/ queja por recurso de inconstitucionalidad denegado en: R.Z.B. c/ GCBA s/ amparo (art. 14 CCABA)", Expte. $N^{\circ} 10425 / 13$, sentencia 31.03.15. 
s/ amparo (art. 14 CCABA) s/ recurso de inconstitucionalidad concedido"63 se resuelven en igual sentido que K.M.P.

Debemos tener en cuenta que el Tribunal Superior de Justicia actualmente cambió su jurisprudencia, ya que en el caso "Q. C., S. Y. c/ Gobierno de la Ciudad de Buenos Aires s/ amparo" 64 revocó el fallo de la instancia anterior y manifestó su postura restrictiva respecto de la aplicación de los instrumentos internacionales y el modo en que el Estado debe implementar los mecanismos para cumplir satisfactoriamente con estos. Tanto en primera instancia como en Cámara, se hizo un análisis pormenorizado y se otorgó una amplia interpretación a las cláusulas de la Constitución Nacional y local, de los instrumentos internacionales, y de las condiciones en las que la actora y su hijo debían ser sujetos de protección por parte del Gobierno de la Ciudad.

Luego se expidió la Corte Suprema de Justicia de la Nación, que hizo lugar a la queja, revocando la sentencia apelada y ordenó al GCBA que

1) Intervenga con los equipos de asistencia social y salud con los que cuenta para asegurar que el niño disponga de la atención y el cuidado que su estado de discapacidad requiere y provea a la actora del asesoramiento y la orientación necesarios para la solución de las causas de su problemática habitacional. 2) Garantice a la actora un alojamiento con condiciones edilicias adecuadas a la patología que presenta el niño, y que se la incluya en algún programa de vivienda en curso o futuro para la solución permanente de la situación de excepcional necesidad planteada.

Para así decidir, el Máximo Tribunal estableció que el sistema de fuentes aplicable al caso está conformado por la Constitución Nacional, los instrumentos internacionales, la Constitución de la Ciudad Autónoma de Buenos Aires y la legislación local dictada en consecuencia. De dicho sistema se desprende el reconocimiento de un derecho de acceso a una vivienda digna y el deber de protección de sectores especialmente vulnerables, como las personas con discapacidad y los niños en situación de desamparo.

\section{B. Buenos Aires}

En la provincia de Buenos Aires, la Suprema Corte de Justicia falló en el año 2013 en el caso "A., G. C. s/ amparo. Recurso extraordinario de nulidad. Recurso extraordinario de inaplicabilidad de ley", ${ }^{65}$ la Cámara de Apelaciones en lo Contencioso Administrativo con asiento en La Plata, confirmó parcialmente la sentencia de primera instancia que, en lo sustancial, hizo lugar a la acción de amparo promovida por la señora G. C. A., en representación

63 TSJ, "Veiga Da Costa, Rocío c/ GCBA s/ amparo (art. 14 CCABA) s/ recurso de inconstitucionalidad concedido", Expte. No 10229/13, sentencia 30.04.2014.

64 CSJN, Fallos: Q. 64. XLVI., sentencia 24.04.2012.

65 SCBA LP A 71535 S 30/10/2013. 
de sus hijos menores de edad, contra la provincia de Buenos Aires y la municipalidad de La Plata, por la cual solicitaban distintas prestaciones alimentarias, de vivienda, de salud y de otorgamiento de subsidios suficientes para acceder a un nivel de vida adecuado, para que las demandadas coordinada y solidariamente provean en un plazo que no exceda los 60 días una vivienda adecuada para la actora y sus tres hijos menores de edad. También ordenó que, hasta tanto las codemandadas den cumplimiento a tal cometido, deberán procurar a su exclusivo costo (y dentro de las siguientes 48 horas) el alojamiento de los nombrados en un hotel o complejo habitacional que reúna las condiciones adecuadas para su habitabilidad por el referido grupo familiar. Finalmente, adecuó la condena en relación al subsidio alimentario, ordenando la inclusión de la amparista y su grupo familiar en un régimen de subsidios mensual que garantice un equivalente al monto móvil del salario mínimo y vital, mientras no varíen las circunstancias fácticas del caso. Cuando el expediente llegó a la Suprema Corte de provincia, y esta, teniendo en cuenta lo sentenciado por la Corte nacional en el caso "Q. C. S.”, confirmó la sentencia de Cámara. Para así decidir, estableció que las prestaciones estatales correspondientes a la realización del derecho a la vivienda, a la salud y a la alimentación, no se traducen en contenidos fijos ni unívocos, en tanto dependen del grado de desarrollo de la sociedad, del diseño de políticas públicas y de las propias circunstancias personales de quienes los demandan; extremos que no pueden obviarse a la hora de encuadrar esta problemática en el acotado marco de un proceso judicial.

Con todo, la senda por la que ha de transitar el reconocimiento de tales derechos ha sido delineada por la Corte Suprema de Justicia de la Nación. Al superar la idea que les asignaba un mero carácter programático, el Alto Tribunal ha dicho que los preceptos que consagran esta clase de derechos sociales poseen una "operatividad derivada" en el sentido de que si bien por su solo enunciado no confieren a los ciudadanos una acción judicial para solicitar su satisfacción (v. Q. 64. XLVI., "Q. C., S. Y. c. Gobierno de la Ciudad de Buenos Aires s/ amparo", sentencia de 24-IV-2012, cons. 11), vinculan y obligan al Estado, al tiempo que permiten a los jueces un escrutinio de razonabilidad y los habilitan para disponer medidas en casos extremos, en cuanto se verifique la afectación de un núcleo esencial que atañe al reconocimiento mínimo e impostergable de tales bienes jurídicos.

Por tanto, que los poderes políticos estén investidos de la atribución e iniciativa para definir el contenido, modo y alcance de las prestaciones sociales básicas no enerva la facultad de reclamo judicial de quien bajo circunstancias apremiantes fuere privado sin razón plausible del acceso a bienes indispensables otorgados a otros. La omisión estatal en tal sentido (como también la ausencia de políticas públicas formalizadas, evaluables y sustentables, para reducir los niveles de exclusión social) desconoce el contenido normativo mínimo de aquellos mandatos o estándares constitucionales autoimpuestos por el Estado. En ese plano — diverso entonces al de la estricta ponderación del mérito de las políticas sociales-cabe situar la intervención judicial en procura de soluciones razonables, a discernirse en el contexto de las 
circunstancias objetivas de cada causa, a favor de aquellas personas que, por su grado de vulnerabilidad, requieren una atención prioritaria o impostergable.

El Alto Tribunal de provincia sentencia del mismo modo en el caso "B. A. F. c/P. d. B. A. s/ amparo. Recurso extraordinario de inaplicabilidad de ley" 66 y en "P., C. I. y o. c/P. d. B. A. s/ amparo. Recurso de inaplicabilidad de ley" ${ }^{67}$

\section{Corrientes}

En la provincia de Corrientes, el Superior Tribunal de Justicia sentenció en el mes de agosto de 2013 en el caso "Ruiz Díaz Mercedes c/ Estado Provincial y Municipal s/ amparo", ${ }^{68}$ teniendo en cuenta la jurisprudencia de la CSJN, que se desprende del caso Quisberth Castro. En esta oportunidad, el Juzgado Civil y Comercial $N^{\circ} 13$ ordena al Estado de la provincia de Corrientes que, en coordinación con la Municipalidad de la ciudad de Corrientes, brinden una solución habitacional a la actora, una mujer viuda, madre de seis hijos, de los cuales tres tienen retardo mental, sin vivienda y sin posibilidades de procurársela. Disconforme con el fallo, la Municipalidad de la ciudad de Corrientes, considerando que no tenía legitimación pasiva en el caso, interpuso recurso de apelación.

El TSJ para sentenciar hace un recorrido por los instrumentos internacionales de derecho humanos, reconocidos por nuestra $\mathrm{CN}$ —art. 75 inc. 22-, además de mencionar a la Constitución Nacional y Constitución local, que protegen el derecho a una vivienda digna y adecuada. Asimismo, argumenta que "la Carta Orgánica de la Municipalidad de la Ciudad de Corrientes establece entre sus fines: Proteger especialmente a la familia, la maternidad, la infancia, la ancianidad y la discapacidad; Proteger al desamparado, especialmente al menor, satisfaciendo sus necesidades básicas; Promover la erradicación de asentamientos urbanos precarios ejecutando planes en coordinación con la Nación y la Provincia”. Entendiendo que, sin lugar a dudas, la demandada tiene legitimación pasiva. Asimismo sostiene que "este panorama exige de la recurrente y codemandada Estado de la Provincia, que pongan a disposición de la actora y sus hijos menores — de forma urgente y de manera coordinada - los planes y equipos de asistencia social diseñados como política pública y conforme se obligaron en el marco jurídico señalado, en pos de proporcionarle a la actora y sus hijos menores discapacitados una vivienda digna para facilitar la superación de la emergencia; hasta tanto se acrediten nuevas circunstancias que confirmen que el estado de necesidad finiquitó”. (considerando VII.)

66 SCBA LP A 70138 S 03/07/2013.

67 SCBA LP A 70717 S 14/06/2010.

68 STJC Expte. No Exp. 56919/10. Sentencia No 204. 


\section{Santa Fe}

La Corte Suprema de Justicia de la provincia de Santa Fe, en el año 2013, falló en el caso promovido por la señora María Eugenia Duarte ${ }^{69}$ contra el Superior Gobierno de Santa Fe, con el objeto de que se le otorgue una vivienda adecuada a su situación de incapacidad y un subsidio mensual para cubrir sus necesidades alimentarias.

En este caso, la Cámara confirma la sentencia de primera instancia, que rechaza el amparo interpuesto. Contra dicho resolutorio, la actora interpuso recurso de inconstitucionalidad.

Como fundamento de tal impugnación, la amparista cuestiona que se haya fallado utilizando como único argumento que la provisión de una vivienda no es una cuestión que pueda resolver la judicatura, sino que resulta una incumbencia del Poder Ejecutivo Provincial.

En este caso, la CSJ de Santa Fe anula la sentencia impugnada, y resuelve en consonancia con la jurisprudencia del más alto tribunal del país, teniendo en cuenta los instrumentos internacionales incorporados a nuestra Carta Magna en la reforma de 1994 —art. 75 inc. 22- y sosteniendo

la necesidad genérica de adoptar medidas de acción positiva a fin de superar situaciones de desigualdad en el goce de los derechos, y especialmente para el caso de las personas con discapacidad, cabe mencionar que las normas aplicables en materia de acceso a la vivienda y a la alimentación —aspectos sustancialmente reclamados en el presente amparo- provienen tanto de fuente nacional como internacional (...). Es en ese contexto que debe examinarse la entidad del derecho vulnerado, ponderado en relación a las circunstancias personales de la demandante y las respuestas que pudiera haber brindado la Administración para evitar la afectación de los derechos de la reclamante, ya que no se está juzgando la efectividad de la política gubernamental sobre discapacidad en general, sino frente a un sujeto particular con una disminución funcional determinada, pues lo que puede resultar suficiente para una generalidad de casos abstractamente considerados puede no serlo para uno en particular y a la inversa. Y, además, la respuesta del Estado debe ser ponderada integralmente, es decir, que debe evaluarse también la actividad que ha desplegado durante el transcurso del proceso, ya que, como enunciado general, las decisiones de los tribunales de justicia deben atender a las circunstancias existentes al momento del fallo, aunque sean sobrevinientes (C.S.J.N., Fallos: 319,79, 1558, 2845 y 331, 2628, entre otros) (Considerandos $4^{\circ}$ y $5^{\circ}$ del voto del Dr. Puccinelli). Resulta claro que una política abstencionista con relación a los derechos de las personas con discapacidad resulta tanto inconstitucional como inconvencional, desde que existe un claro deber de adoptar respecto de ellas medidas de acción positiva hasta el máximo de los recursos disponibles y que el Poder Judicial — lejos de violentar la división de

69 CSJSF, "Duarte, María Eugenia c/ Provincia de Santa Fe - Amparo s/ recurso de inconstitucionalidad (concedido por la Cámara)”. Fecha: 20/11/2013. 
poderes o de convertirse en un Poder Ejecutivo bis - tiene el deber de verificar si la negativa de ciertas prestaciones mínimas es o no razonable. Adquiere a este respecto especial relieve lo resuelto por la Corte Nacional el 24/04/12 en "Q. C., S. Y. c. Gobierno de la Ciudad de Buenos Aires" (LL, 2012-C-257), cuando el tribunal cimero nacional con el voto conjunto de los señores ministros doctores Lorenzetti, Highton de Nolasco, Fayt, Maqueda y Zaffaroni, revocó la sentencia del Superior Tribunal de Justicia de la Ciudad Autónoma de Buenos Aires y ordenó al Gobierno local que garantice a una madre y su hijo discapacitado, que se encontraban en "situación de calle", un alojamiento con condiciones edilicias adecuadas, sin perjuicio de contemplar su inclusión en algún programa de vivienda en curso o futuro para la solución permanente de la situación de excepcional necesidad planteada. (Considerando $7^{\mathrm{o}}$.)

\section{E. Chaco}

En el marco de la causa "Rodríguez, Santa Leticia c/ González, Ricardo y/o cualquier otro ocupante s/ desalojo", ${ }^{70}$ en la que se ventilaba un proceso de desalojo, la Sala Primera de la Cámara de Apelaciones en lo Civil y Comercial resolvió confirmar la sentencia dictada en primera instancia, pero antes del desalojo y debido a la presencia de menores en la vivienda objeto del reclamo, establece que resulta indispensable darle intervención al asesor de menores con el objeto de que adopte los recaudos legales necesarios para proteger los derechos de los niños que pudieren resultar afectados como consecuencia del desalojo.

Paralelamente, procede anoticiar el caso en estudio al Poder Ejecutivo de la provincia del Chaco, a través de la Subsecretaría de Niñez, Adolescencia y Familia, dependiente del Ministerio de Desarrollo Social, para que, en su condición de poder administrador y ejecutor de las políticas públicas para hacer efectivos el derecho constitucional de acceso a la vivienda digna, tome las medidas conducentes para la inclusión del demandado y su grupo familiar en las acciones encaradas para resolver la problemática habitacional de la población, si se hallare efectivamente en situación que requiera ser tutelada. (Considerando VIII de la Dra. María Ester Anadón Ibarra de Lago.)

La Cámara fundamenta su decisión en la Constitución Nacional, la Declaración Universal de los Derechos Humanas, y el Pacto Internacional de Derechos Económicas, Sociales y Culturales, así como la Convención sobre los Derechos del Niño.

\section{F. Neuquén}

La Cámara Única Provincial de Apelaciones en lo Civil, Comercial, Laboral, Minería y Familia resolvió la apelación interpuesta por la parte demandada en el caso "Defensores de

70 “Rodríguez, Santa Leticia c/ González, Ricardo y/o cualquier otro ocupante s/ desalojo”. Expediente N 3384, año 2010, sentencia del 18-06/2014, Sala Primera de la Cámara de Apelaciones en lo Civil y Comercial. 
los Derechos del Niño y Adolescente E/R de los menores C.M.E; C.L.S.; G.M.A. y B.O.M c/ Provincia del Neuquén s/ acción de amparo", ${ }^{71}$ contra la resolución de Primera Instancia que hizo lugar al amparo. La Defensora de los Derechos del Niño, en representación de los menores de autos, inicia acción de amparo con el objeto que se haga efectiva la operatividad derivada del derecho a una vivienda digna, a efectos de preservar la vida y la salud de los menores que se encuentran en una situación de vulnerabilidad extrema. La Cámara confirma la sentencia apelada fundamentando su decisorio en: 1) que "(...) resulta incuestionable que la garantía de salud de los niños representados por la funcionaria del Ministerio de la Defensa, impone la provisión de una 'vivienda adecuada', de conformidad a los parámetros emergentes de los tratados internacionales que fueran desbrozados meticulosamente por la Sra. Juez de grado a efectos de dar sustento al decisorio impugnado. En conclusión, atendiendo a la índole de los derechos humanos cuya protección se peticiona en los presentes, aparece indudable que el amparo es el cauce procesal más idóneo para dar respuesta judicial al objeto de esta Litis. (...)" (Considerando A.2); y 2) "(...) las medidas de acción positiva adoptadas por el Estado no han resultado suficientes para concretar el mandato constitucional que impone asegurar a los niños en grave estado de vulnerabilidad el acceso a una vivienda adecuada, atento a que la provista hasta el presente por el municipio local no satisface los estándares mínimos de salubridad, higiene y seguridad necesarios para preservar la salud e integridad física, psíquica y moral de aquellos.(...)" (Considerando B.2).

Fundamentando su postura en la Constitución Nacional y los instrumentos internaciones de derechos humanos, entre los que se mencionan la Convención de los Derechos del Niño y el PIDESC, así como en el caso "B.A.F. c/ provincia de Buenos Aires s/ amparo. Recurso extraordinario de inaplicabilidad de ley", que se menciona en el análisis jurisprudencial de la provincia de Buenos Aires.

\section{G. Tierra del Fuego}

Analizaré una sentencia de la Sala Civil, Comercial y del Trabajo de la Cámara de Apelaciones provincial que resuelve un recurso de apelación interpuesto en los autos "Castro, Claudia Rosana c/ I.P.V. s/ amparo". ${ }^{72}$

En primera instancia se rechazó la acción de amparo promovida por la señora Claudia Rosana Castro, por su propio derecho y en representación de sus hijos menores contra el Instituto Provincial de la Vivienda debido a que el lugar donde viven actualmente no se encontraría

71 "Defensoría de los Derechos del Niño y Adolescente E/R de los menores C.M.E; C.L.S.; G.M.A. y B.O.M c/ Provincia del Neuquén s/ acción de amparo", Expte. N 7666 - Año 2014, Sala II.

72 Sala Civil, Comercial y del Trabajo de la Cámara de Apelaciones de Tierra del Fuego. Autos No 19208/14 provenientes del Juzgado de Primera Instancia en lo Civil y Comercial No 2 Distrito Judicial Sur, en los autos caratulados: "Castro, Claudia Rosana c/ I.P.V. s/ amparo", en trámite por ante este Tribunal de Alzada bajo el No 7190/14. 
en condiciones de habitabilidad. El grupo familiar se compone de varios menores, uno de ellos con incapacidad temporaria, un bebé de apenas meses de vida y un señor de avanzada edad que alega padecer problemas de visión, siendo la propia amparista la que afirma que los ingresos familiares ascienden a la suma de \$13 600. Contra la sentencia de la primera instancia, la actora interpone recurso de apelación argumentando que reclama la intervención y asistencia concreta del Estado en lo pertinente a la satisfacción de los derechos basales, entre ellos, el acceso a una vivienda digna, segura y adecuada. Además, afirma que se encuentra sin la solución habitacional que oportunamente requirió a la demandada. Fundamentando que su derecho se encuentra protegido por cláusulas de raigambre constitucional y el Pacto Internacional de Derechos Económicos Sociales y Culturales principalmente. La Sala Civil, Comercial y del Trabajo de la Cámara de Apelaciones provincial resuelve en este caso rechazando el recurso interpuesto considerando

que a los fines de hacer valer el derecho constitucional a una vivienda digna como se pretende en la presente acción de amparo, resulta imprescindible demandar al Estado provincial, Ministerio de Desarrollo Social o cualquier otro organismo capaz de entender acabadamente la situación de autos. Ello en virtud de que las obligaciones previstas en nuestra Constitución provincial (arts. 20, 23 y 28) resultan exigibles directamente al Estado y no así a un ente autárquico que, si bien tiene funciones tendientes a brindar soluciones habitacionales, se encuentra sujeto al plan global de la provincia de Tierra del Fuego — véase artículo 5 de la Ley Provincial No 19". (El subrayado me pertenece) (Considerando V del voto del Dr. Ernesto Adrián Löffler).

Antes de continuar con los argumentos esgrimidos por la Cámara para rechazar el recurso, es dable hacer una reflexión al respecto de lo trascripto en el párrafo anterior, sobre la posición contradictoria para fundamentar esta decisión de rechazo, es decir, que primeramente sostiene el Dr. Loffler que la actora debió demandar al "Estado provincial, Ministerio de Desarrollo Social o cualquier otro organismo capaz de entender acabadamente la situación de autos". Acaso no resulta ser el Instituto Provincial de la Vivienda, otro organismo capaz de entender acabadamente en la situación de autos, asimismo y como manifiesta el Juez opinante 
el art. $5^{73}$ de la ley que crea el Instituto Provincial de la Vivienda, ${ }^{74}$ textualmente dice que "a) (...) asumirá con exclusividad la coordinación de las acciones y recursos técnicos, humanos y financieros que promuevan o dispongan los organismos internacionales, nacionales, provinciales, municipales o privados y entidades intermedias que actúen en esta área; b) promover la solución integral al problema de vivienda, priorizando la atención de los núcleos familiares más necesitados; etc.”.

Más allá de entender que la actora debió demandar al Estado provincial, no puede negarse que el Instituto Provincial de la Vivienda es un organismo que cumple los requisitos para tener legitimación pasiva en el caso en análisis; asimismo, los derechos reconocidos constitucionalmente resultan vacíos cuando los magistrados los utilizan en sus sentencias, en detrimento de quien pretende la aplicación efectiva de los mismos.

Al final del considerando $\mathrm{V}$, el camarista hace un análisis de lo que hubiera pasado si la amparista hubiera demandado al Estado provincia, pues es claro que este argumento resulta sin sentido alguno, puesto que el Estado provincial no fue demandado en autos.

73 Artículo 5․ El Instituto Provincial de Vivienda cumplirá los siguientes objetivos y funciones generales: a) diseñar y ejecutar la política habitacional provincial acorde al plan global del Gobierno de la provincia de Tierra del Fuego, Antártida e Islas del Atlántico Sur. En tal concepto, asumirá con exclusividad la coordinación de las acciones y recursos técnicos, humanos y financieros que promuevan o dispongan los organismos internacionales, nacionales, provinciales, municipales o privados y entidades intermedias que actúen en esta área; b) promover la solución integral al problema de vivienda, priorizando la atención de los núcleos familiares más necesitados; c) contemplará la requisitoria efectuada por aquellos aspirantes de estado civil soltero, divorciado o viudo sin familiares a cargo; d) promover la federalización de la política habitacional y de los recursos que a ese fin destine la Nación; e) asistir con la aplicación de los programas de vivienda, equipamiento comunitario e infraestructura de servicio, al desarrollo, mejoramiento y consolidación de centros poblados y al asentamiento de población en áreas rurales; f) concurrir en su área específica, al desarrollo de las zonas de frontera, coordinando acciones con las autoridades responsables de la fijación de políticas de frontera en el orden nacional o provincial; g) proponer, mediante el adecuado planeamiento físico y utilización de recursos a su alcance, el mejor y más racional uso de la tierra y de las mejoras urbanas, especialmente en los conjuntos, ejecutados por el Instituto y de acuerdo a la normativa municipal vigente; $h$ ) estudiar, desarrollar y promover la utilización de tecnologías de diseño, producción y construcción de viviendas adecuadas a la realidad física y social de la Provincia; i) mantener vinculación permanente con los organismos dedicados al estudio e investigación de los problemas habitacionales en los aspectos técnicos, sociales y de planificación, sean de la esfera estatal o privada, nacional o del exterior; j) promover, ya sea mediante la licitación de terrenos propiedad del Instituto u otra modalidad, la construcción privada de equipamientos comerciales y de servicios necesarios en conjuntos habitacionales ejecutados por el Instituto; k) analizar, desarrollar y promover la utilización de materiales de construcción de origen local, como así también el empleo de energías no convencionales; l) promover, colaborando con los Municipios y Comunas mediante planes adecuados, el saneamiento urbano-ambiental y la sustitución, readecuación, terminación o relocalización de viviendas precarias en áreas urbanas; ll) canalizar la actividad del FONAVI en la Provincia, ejecutando todos los actos y contrataciones que sean necesarios para el cumplimiento de los objetivos de la ley de creación del citado Fondo y sus modificatorias; m) administrar los aportes o el financiamiento de obras para la Provincia que tengan origen en la Secretaría de Vivienda y Calidad Ambiental de la Nación y todo otro fondo provincial destinado a la vivienda, realizando los actos y contrataciones necesarios para la ejecución de las obras. n) proteger el medio ambiente en relación a sus actividades instrumentando los medios para la evaluación previa del impacto ambiental; ñ) establecer las pautas de aptitud técnica de las viviendas en relación a las condiciones climáticas, geográficas y sociales de la zona.

74 Ley No 19. Instituto Provincial de Vivienda: Creación. Sanción: 08 de julio de 1992. Promulgación: 27/07/92 D.P. No 1272. Publicación: B.O.P. 31/07/92. 
Por otro lado, al demandar al Estado provincial, se garantiza el derecho de defensa de este último, el cual puede dar cuenta si en la actualidad se encuentra articulando los mecanismos necesarios a los fines de contener la situación de extrema vulnerabilidad que dice sufrir el amparista. Es el propio recurrente quien en su recurso de apelación expresa que existen "extremos objetivos que reclaman la intervención y asistencia concreta del Estado". Sin embargo, el Estado provincial no fue demandado en estas actuaciones y por tal motivo esta Alzada se encuentra impedida de ordenar medidas contra quien no ha sido parte del proceso ni contra aquellos entes autárquicos que no son garantes de los derechos plasmados en nuestra Constitución provincial.

\section{H. Santa Cruz}

En este caso, ${ }^{75}$ los Defensores Oficiales Titulares de las Defensorías Oficiales $\mathrm{N}^{\circ}$ Uno y Dos de Menores de la ciudad de Río Gallegos interponen acción de amparo contra el Poder Ejecutivo Provincial, Ministerio de Desarrollo Social, Subsecretaría de Niñez Adolescencia y Familia, y Ministerio de Economía de la Provincia de Santa Cruz, con el objeto de que se regularice la deuda en el pago de salarios a los encargados y operadores del sistema de 'hogares alternativos' (Sistema de Abrigo Sociofamiliar), dependiente del Ministerio de Desarrollo Social de la provincia de Santa Cruz, correspondiente a los meses de julio, agosto y septiembre de 2012, como asimismo el pago de las asignaciones que corresponde a cada niño, niña o adolescente alojados en los hogares del Estado.

El caso llega al Tribunal Superior de Justicia a través de un recurso de casación interpuesto por la parte actora, el tribunal resuelve hacer lugar al amparo, e intimar al Poder Ejecutivo a reglamentar los artículos 46 y 47 de la Ley Provincial No 3062, en el plazo de 60 (sesenta) días, bajo apercibimiento de aplicación de astreintes en caso de incumplimiento, y estableciendo que dicha reglamentación deberá ajustarse a las consideraciones establecidas en el considerando X:

Que la reglamentación deberá tener en cuenta: a) Que se garantice prioritariamente el ejercicio y disfrute pleno, efectivo y permanente de aquellos derechos reconocidos por la Ley 3062, procurando los mecanismos necesarios y ágiles para dar cumplimiento en tiempo y forma a los pagos de las sumas que corresponda abonar en virtud de las obligaciones previstas en la misma; b) Que el "Fondo" específico previsto en el art. 47 de la Ley 3062 sea incorporado en forma directa y circunstanciada en el Proyecto de Ley de Presupuesto, garantizando la intangibilidad y ejecutividad de los fondos, permitiendo de este modo un manejo contable y administrativo acorde a las necesidades del sistema; c) Que en términos cuantitativos, la asignación dineraria a establecer sea suficiente para cubrir gastos de alimento, salud, vivienda, educación, higiene, vestimenta y esparcimiento de los niños, niñas

\footnotetext{
75 "Defensoría Oficial No Uno de Menores y otra c/ Subsecretaría de Niñez, Adolescencia y Familia y otros s/ acción de amparo", Expte. No D-15.194/12 (D- 1.903/13-TSJ), sentencia 20 de diciembre de 2013.
} 
y adolescentes que han sido puestos bajo la tutela estatal con la finalidad de ser protegidos, en los términos de la Ley 3062, teniendo presente el 'Interés Superior del Niño'; d) Que sea tomado como referencia para establecer el tope mínimo de la asignación correspondiente a cada niño, niña y/o adolescente incluido en el Sistema de Abrigo Sociofamiliar (y/o sistema de 'pequeños hogares'), el cincuenta por ciento (50 \%) del Salario Mínimo Vital y Móvil, y en caso de niños con discapacidad se estipule el setenta por ciento $(70 \%)$ de idéntico baremo; e) Que se establezca un mecanismo de readecuación anual contemplativo de la evolución del Salario Mínimo Vital y Móvil.

Para así decidir, el Tribunal Superior de Justicia tuvo especial atención en que

frente a este escenario de incumplimientos reiterados, de omisiones y negligencias estatales por parte del Poder Administrador en lo que respecta a la reglamentación de la ley 3062, la opción legítima que cabe a este Alto Cuerpo consiste en conminar al Poder Administrador a la reglamentación de los arts. 46 y 47 de la ley $\mathrm{N}^{\circ} 3062$, teniendo presentes determinadas pautas orientativas para satisfacer adecuadamente las necesidades materiales de los niños y adolescentes institucionalizados, particularmente respecto de la nutrición (arts. 4.1 y 19 CADH, y 10.3 PIDESC), el vestuario y la vivienda (art. 27.3 CDN). Se debe garantizar un minimum tuitivo, que debe ser respetado.

Asimismo, este tribunal consideró que

Resta que el Tribunal Superior de Justicia acompañe con sus pronunciamientos la reparación de omisiones inconstitucionales que corroen los cimientos del edificio de la Constitución $-\mathrm{y}$, por ende, del tejido social mismo- . Y, paralelamente, que garantice con su accionar jurisdiccional [...] la operatividad de los derechos y garantías reconocidos en la Ley Fundamental. ${ }^{76}$ (Considerando IX.)

\section{CONCLUSIÓN}

En el contexto analizado en el presente artículo puedo afirmar que las "políticas públicas" implementadas no resultan suficientes para resolver la problemática habitacional, que se manifiesta en situaciones similares en diferentes provincias del territorio argentino. Se evidencia que los poderes políticos no están a la altura de las circunstancias, mostrándose indiferentes.

Frente a esta situación de vulnerabilidad absoluta que viven ciudadanos y niños es que se judicializan los casos con el objeto de lograr que el Estado al fin se ocupe de ellos. En los casos de jurisprudencia analizados, podemos observar la aplicación de los instrumentos internacionales con jerarquía constitucional, en especial el PIDESC, y la jurisprudencia del más alto

76 Víctor Bazán, "Hacia la plena exigibilidad de los preceptos constitucionales: el control de las omisiones inconstitucionales. Especial referencia a los casos de Brasil y Argentina”, en Inconstitucionalidad por omisión, coordinado por Víctor Bazán (Santa Fe de Bogotá: Temis, 1997), 83. 
tribunal receptada en los tribunales locales, entendiendo que los magistrados deben realizar el debido control de convencionalidad.

Asimismo, son los otros dos poderes (Ejecutivo y Legislativo) los que deben, a través de las leyes y de las políticas públicas, dar efectiva protección y cumplimiento al derecho a una vivienda digna consagrado no solo en la Constitución Nacional sino también receptado en las constituciones locales. Aun en el entendimiento de que existe un andamiaje jurídico referido al acceso a la vivienda digna, se ve claramente que la protección real y efectiva hasta el momento no ha sido lograda.

\section{REFERENCIAS}

- Bazán, Víctor. “El control de la convencionalidad: incógnitas, desafíos y perspectivas”. En Contextos, una publicación del Seminario de Derecho Público de la Defensoría del Pueblo de la Ciudad Autónoma de Buenos Aires, N 5 (abril de 2013).

"Hacia la justiciabilidad directa de los derechos económicos, sociales y culturales en el sistema interamericano”. La Ley (11/02/2015): 1.

"Hacia la plena exigibilidad de los preceptos constitucionales: el control de las omisiones inconstitucionales. Especial referencia a los casos de Brasil y Argentina”. En Inconstitucionalidad por omisión, coordinado por Víctor Bazán. Santa Fe de Bogotá: Temis, 1997.

- Duacastella Arbizu, Luis E. y María Andrea Mercado. "La desprotección de la mujer en el programa de restauración del daño ambiental colectivo de la Cuenca Matanza - Riachuelo". Revista Institucional de la Defensa Pública de la Ciudad Autónoma de Buenos Aires, Año 4, N. ${ }^{\circ} 6$ (diciembre de 2014): 150.

- Gil Domínguez, Andrés. Derechos, racionalidad y última palabra. Primera edición. Buenos Aires: Ediar, 2014.

- Jimenes, Eduardo. “¿Qué son los derechos humanos?”. En Derechos humanos y control de convencionalidad, coordinado por Mario Midon. ConTexto, 2016.

- Loianno, Adelina. "Funcionamiento de los órganos de protección de los derechos humanos. Algunas cuestiones acerca de las condiciones de eficacia del SIDH". En Derechos humanos y control de convencionalidad, coordinado por Mario Midon. ConTexto, 2016.

- Manili, Luis P. El bloque de constitucionalidad, la recepción del Derecho Internacional de los Derechos Humanos en el Derecho Constitucional Argentino. Buenos Aires: La Ley, 2003.

- Manili, Pablo Luis. "La difícil tarea de definir el concepto de derechos humanos". En Derechos humanos y control de convencionalidad, coordinado por Mario Midon. ConTexto, 2016. 
- Mantaras, Pablo C. "El control de convencionalidad en el ámbito del poder judicial de la ciudad autónoma de buenos aires. Perspectivas actuales y desafíos futuros". En Centro de Formación Judicial, 15 años del centro de formación judicial, 247-265. Ciudad Autónoma de Buenos Aires: Jusbaires, 2014.

- Pizzolo, Calogero. "Las normas interconectadas. Entre la primera y la última palabra en derechos humanos". La Ley (08/07/2015): 1. Cita online: AR/DOC/2156/2015.

- Rosatti, Horacio. Tratado de derecho constitucional. Tomo I. Primera edición. Santa Fe: Rubinzal Culzoni, 2010.

\section{JURISPRUDENCIA}

- Corte IDH, Caso "Trabajadores cesados del Congreso (Aguado Alfaro y otros) vs. Perú", sentencia de Excepciones Preliminares, Fondo, Reparaciones y Costas, 24 de noviembre de 2006, Serie C, No 158; voto razonado del Juez Sergio García Ramírez, párr. 11.

- Corte IDH, Caso "Almonacid Arellano y otros vs. Chile", sentencia 18.11.2010, párr. 117 y 124.

- Corte IDH “Trabajadores cesados del Congreso vs. Perú (Aguado Alfano y otros)”, sentencia 24.112006, párr. 128.

- Corte IDH, "La Cantuta vs. Perú”, sentencia 29.11.2006, párr. 173.

- Corte IDH, “Fontevecchia y D’amico vs. Argentina”, sentencia 29.11.2011, párr. 93.

- CSJN, Fallos 315: 1492, "Ekmekdjian, Miguel A. c. Sofovich Gerardo y otros", sentencia 07.07.1992.

- CSJN, R.401. XLIII, "Rodríguez Pereyra, Jorge Luis contra el Ejército Argentino", sentencia 27.11.2012.

- CSJN, G.147. XLIV, "García Méndez, Emilio y Musa, Laura Cristina s/ causa N ${ }^{\circ}$ 7537”, sentencia 02.12.2008.

- CSJN, G. 291. XLIII, "Gualtieri Rugnone de Prieto, Emma Elidia y otros s/ sustracción de menores de 10 años", sentencia 11.08.2009.

- CSJN, Fallos 330: 3248, sentencia 13.07.2007.

- CSJN, Fallos 330:3248, sentencia 31.08.2010.

- CSJN, Fallos: Q. 64. XLVI., sentencia 24.04.2012.

- CSJSF, "Duarte, María Eugenia c/ Provincia de Santa Fe - Amparo s/ recurso de inconstitucionalidad (concedido por la Cámara)". Fecha: 20/11/2013. 
- "Defensoría de los Derechos del Niño y Adolescente E/R de los menores C.M.E; C.L.S.; G.M.A. y B.O.M c/ Provincia del Neuquén s/ acción de amparo”, Expte. № 7666 - Año 2014, Sala II.

- "Defensoría Oficial No Uno de Menores y otra c/ Subsecretaría de Niñez, Adolescencia y Familia y otros s/ acción de amparo", Expte. No D-15.194/12 (D- 1.903/13-TSJ), sentencia 20 de diciembre de 2013.

- Ley No 19. Instituto Provincial de Vivienda: Creación. Sanción: 08 de julio de 1992. Promulgación: 27/07/92 D.P. No 1272. Publicación: B.O.P. 31/07/92.

- "Rodríguez, Santa Leticia c/ González, Ricardo y/o cualquier otro ocupante s/ desalojo”. Expediente No 3384, año 2010, sentencia del 18-06/2014, Sala Primera de la Cámara de Apelaciones en lo Civil y Comercial.

- Sala Civil, Comercial y del Trabajo de la Cámara de Apelaciones de Tierra del Fuego. Autos No 19208/14 provenientes del Juzgado de Primera Instancia en lo Civil y Comercial No 2 Distrito Judicial Sur, en los autos caratulados: "Castro, Claudia Rosana c/ I.P.V. s/ amparo", en trámite por ante este Tribunal de Alzada bajo el No 7190/14.

- SCBA LP A 71535 S 30/10/2013.

- SCBA LP A 70138 S 03/07/2013.

- SCBA LP A 70717 S 14/06/2010.

- STJC Expte. No Exp. 56919/10. Sentencia No 204.

- TSJ "GCBA s/ queja por recurso de inconstitucionalidad denegado en: Duhalde, Alejandra Viviana c/ GCBA y otros s/ amparo (art. 14 CCABA)”, Expte. No 10954/14, sentencia 04.02.15.

- TSJ, "GCBA s/ queja por recurso de inconstitucionalidad denegado en: Sarubbi, Rosa Haydee y otros c/ GCBA y otros s/ amparo (art. 14 CCABA)”, Expte. No 10695/14, sentencia, 17.12.14.

- TSJ, "GCBA s/ queja por recurso de inconstitucionalidad denegado en: K.M.P c/ GCBA y otros s/ amparo (art. 14 CCABA)”, Expte. 9205/12, sentencia 21.03.2014.

- TSJ, "GCBA s/ queja por recurso de inconstitucionalidad denegado en: R.Z.B. c/ GCBA s/ amparo (art. 14 CCABA)", Expte. N 10425/13, sentencia 31.03.15.

- TSJ, "Veiga Da Costa, Rocío c/ GCBA s/ amparo (art. 14 CCABA) s/ recurso de inconstitucionalidad concedido", Expte. N 10229/13, sentencia 30.04.2014. 